\title{
SHARING URBAN RENEWABLE ENERGY GENERATION SYSTEMS AS PRIVATE ENERGY COMMONS
}

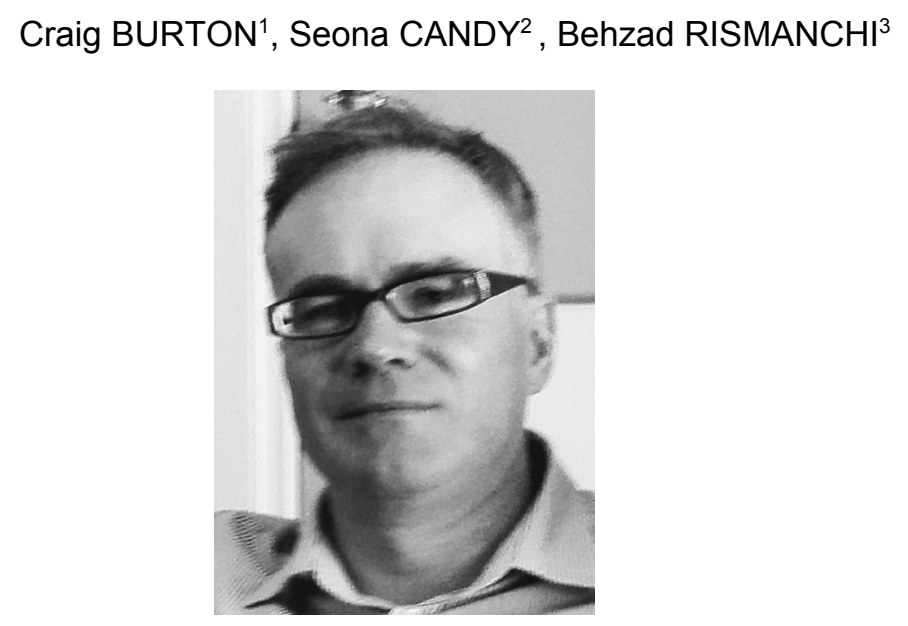

1 Faculty of Architecture, Building and Planning, University of Melbourne, Australia, cburton2@student.unimelb.edu.au

2 Faculty of Architecture, Building and Planning, University of Melbourne, Australia, candys@unimelb.edu.au

3 Faculty of Engineering, University of Melbourne, Australia, behzad.rismanchi@unimelb.edu.au

Keywords: solar power, commons theory, microgrid, behaviour change, energy sharing

\begin{abstract}
This study tested a new methodology for simulating shared electricity generation among small groups of neighbours with Ostrom (1994) principles of common pool resource (CPR) (human behaviour-based) efficiencies. The approach does not not anticipate exclusive off-grid communities but instead, diverse energy users taking advantage of the averaging effects of aggregation, the social benefits of a CPR and direct action on emissions. The study tested three groups of 5 adjacent- or same-building- neighbours for three months to measure how electricity demand (import) is affected by an in-home display issuing nudges and sanctions by the group around a simulated (limited capacity) shared solar and battery system. A control group of 6 homes' energy data was obtained for the same period. All three groups reduced their energy demand with weak but significant correlation between stimulus and reduced energy demand and one group significantly shifted demand toward available shared solar energy resources during the intervention.
\end{abstract}

\section{Introduction}

The present trajectory for the Energy Transition in Australia in the absence of substantial demand management for electricity will see a doubling of demand to 2050 (CSIRO and ENA, 2015) and the likely scale of renewables being twice the nameplate capacity of despatchable generators (AEMO, 2013) in order to compensate for variability. That is, four times the generation power of 2018 carbon-based generators may be needed in 2050. The transition to very low carbon has already been estimated to cost AUD1,140 billion (CSIRO and ENA, 2015), a large component of this cost being met by private solar owners.

Accordingly, some form of demand management is often assumed to occur in popular "zero carbon" plans (for example (Ison \& Lyons, 2013)) to the extent that electricity demand is expected to be halved. Usually this is proposed to occur through efficiency gains. However, a turnaround in demand of this magnitude would be unprecedented (Kelly, 2010). This electricity demand history is already moderated by long running government programmes for energy efficiency, behaviour change, domestic solar stimulus, electricity price increases and other effects that should suppress demand. These are delivered via energy saving information (DELWP, 2014) 
but also efficient device labelling (DEE, 2018), efficient product rebates, solar tariffs (DELWP, 2016) and others. The motivations for these approaches include that energy consumers can change their habits. However, the literature increasingly does not support this.

\section{Demand management}

Demand management is a mature field and it has rested heavily on Bandura's Theory of Planned Behavior (TPB) (Bandura, Boone, Reilly, \& Sashkin, 1977). The fundamental premise of this approach is that consumers are rational and when served with information and incentives, they will choose to consume differently. Studies of studies (Delmas, Fischlein, \& Asensio, 2013) find that the largest effects of very many forms of demand management signals based on TPB seem to have a final impact on actual electricity demand of only $10 \%$, usually less, and with many studies having identified methodological problems (also (Abrahamse, Steg, Vlek, \& Rothengatter, 2005)). That is, interventions ranging from rewards, to goals, penalties, pecuniary incentives, home audits and others do not have large effects on actual demand and often the removal of the intervention results in demand returning to where it was. Most recently, a campaign for low-income families in several cohorts across Australia $(n=18889)$ with respondents self-reporting changed energy practices $(30-80 \%$ reported changes) after efficiency interventions were able to reduce their demand by only $2-12 \%$ (Russell-Bennett et al., 2017). Consumers are informed, they make changes to their routines, but the returns in avoided energy demand are small.

The challenge of demand management likely has at least four impediments: campaigns typically deal with the consumer in insolation, in the absence of their social environment or even family environment (for example (Lowe, Lynch, \& Lowe, 2015)); electricity is offered as limitless, cheap and highly reliable (Abbott, 2001); electricity use is very difficult to disaggregate from social practices (Shove \& Walker, 2014); and, there are no consequences for high demand - only higher electricity bills.

There are of course some notable exceptions to these. High-touch interventions such as personal in-home audits perform well compared to others (Delmas et al., 2013). High-tech interventions such as in-home displays (IHDs) have been observed to bring about a $20 \%$ reduction in electricity demand (Gans, Alberini, \& Longo, 2013) and finally, the subject of this study, social approaches to sustainability (EcoTeams, energy communities), have established long running energy conservation behaviours that even improve in time (Hargreaves, Nye, \& Burgess, 2008).

Reframing within social structures already seems successful for demand management in water. Prior to the Victorian Millennium drought (1999-2009) water was felt to be inexpensive, unlimited and reliable (Allon \& Sofoulis, 2006, p. 49) - as electricity is presently understood by consumers. Melbournians discuss water now as a limited and valuable resource after a large utility-led demand programme (Liubinas \& Harrison, 2012). Can such a re-framing be achieved for electricity? This may certainly be harder to bring about because the visible impact of the drought has no equivalent for energy, and even the very likely climate change effects behind the large bushfires of 2009 were attributed to ocean currents (Australian Bureau of Meteorology, 2014) and not human-forced climate change. Simulating a re-framed electricity supply may cause greater conservation, but the re-framing itself needs to be compelling.

\subsection{Commons}

This study proposed another way to potentially re-frame the electricity supply as a means to conservation - that electricity should be presented as a Common Pool Resource (CPR) which is managed by a commons system. Traditionally CPRs have been natural resources which have limited productivity and have to be managed by those who appropriate from them. Not managed properly, the resource is overused and it collapses. Elinor Ostrom's work Rules, Games and Common Pool Resources (1994) spells out eight design principles for commons which have since been rigorously tested in hundreds of studies (Cox, Arnold, \& Villamayor Tomás, 2010). It is also promising that rural and isolated distributed renewable energy systems can be successfully shared and that the naturally limited performance of the systems can be accomodated in behaviour changes (for 
example see (Gardiner, 2017)). Similarly commons systems successfully self-manage shared pasture, fisheries and forests. Can there be urban energy commons?

\subsection{Commons theory}

Ostrom's principles are derived from observations of (very broadly): borders, appropriation and maintenance, rule-making, monitoring, sanctions, conflict resolution, government interference, and scale. The definition of a managed commons is still not broadly understood - Wikipedia is not a managed commons: it is certainly managed and has its own system of governance and rules, but anyone can consume a Wikipedia article without impacting other users (it is not rivalrous, and there are no sanctions for misusing it). This makes Wikipedia a public good. Less certain are club goods or toll goods (Bollier, 2014) such as a collective solar and battery system that is owned in shares. This is not a commons according to Ostrom's principles because access to the toll good is artificially limited (by access limited to owners) and non-rivalrous (until there is congestion) (Ostrom et al., 1994, p. 7). Instead the energy commons (the non-stationarity) was defined in this research as the collective energy sharing agreement itself. To test this, the applicability of commons principles for sharing energy, principles 4 and 5, monitors and graduated sanctions (respectively) were chosen for testing because these principle were most often absent from public goods and toll goods management.

Electricity use at present occurs without any kind of signals about limits, let alone reciprocity. That is, one can use a large amount of electricity and apart from an eventual large bill there are no consequences. Since electricity costs no more than fifty cents a $\mathrm{kWh}$, it may cost a fifty dollars to run a large air conditioner in summer. In reality, running a large air conditioner on the hottest days of the year can cost the utility AUD1,500 (Wood, Carter, \& Harrison, 2014, p. 9) to deliver the electricity to one air conditioner. This is because in fact, electricity is rivalrous at the extremes and the cost of peak demand infrastructure (to support the grid for the top 10 demand days a year) exceeded 45 billion dollars over the last 10 years (Hill, 2014). This signal, however, is completely hidden from residential consumers and this high cost is spread across all electricity users, whether they use air conditioning or not.

The energy source to share in the proposed commons is a fictitious shared solar and battery system that a group of adjacent neighbours will operate and use. This system could be placed on the larger roofs and batteries installed on some of the other houses or where there is space. They are privately connected together (on a private easement) or there is some arrangement with a retailer to allow the exchange of electricity to happen among them via the distribution system. The homes (or in fact flats in the same building) are adjacent because a real private easement would require this, but also there is likely social cohesion among such homes which is identified as valuable for CPRs (Bollier, 2014). Avoiding opt-in for energy sharing (instead recruiting with a spatial constraint) should reduce some self-selection effects in energy collectives (Bauwens \& Eyre, 2017).

Thus the methodological approach considers the impediments listed above and attempts to meet or avoid them: the intervention targets the group as the subject, not the individual home - it is asserted here that this will take advantage of group effects. Second, the electricity supply is re-framed to a limited and valuable resource; the intervention does not rely on signals that target disaggregated behaviours; and, a social sanctions approach is proposed (as part of a commons system) so that there are social outcomes for using electricity at the extremes. The apparatus is an in-home display (IHD), a form of energy use feedback that has rendered promising results for self-management of electricity demand.

\section{In home display}

In order to signal to home occupants that they are draining a rivalrous, limited electrical supply, an in-home display was built for this study. The device is a Raspberry pi microcomputer with a 7-inch touchscreen in a 3D printed case. The computer has a $3 G$ cell modem and a Radiohead low power packet radio receiver. An accompanying smart meter reader was created that counts the LED flashes on two brands of smart meters and radios the count to the IHD in the home. Twenty of each device (IHD and reader) were made. This setup is 
similar to the proprietary Watt's Clever IHD system (SmartUser, 2018) except that the study system is a networked colour touchscreen display with Linux operating system.
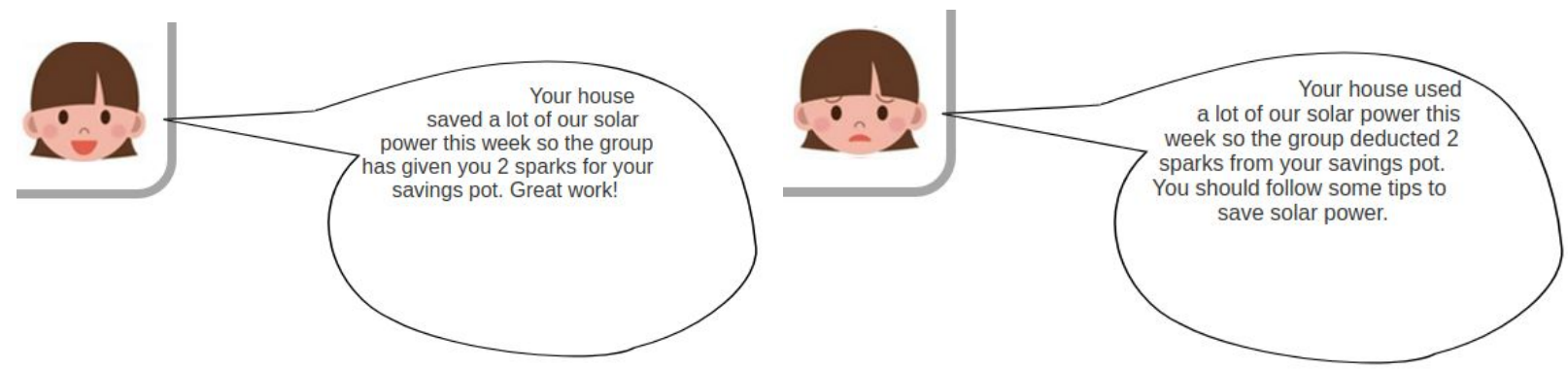

Figure 1: Negative and positive sanction triggered by home energy demand cause solicitations to the other group members, who may choose to fine or reward the household. An avatar, Rachel, reports the outcome to the affected household
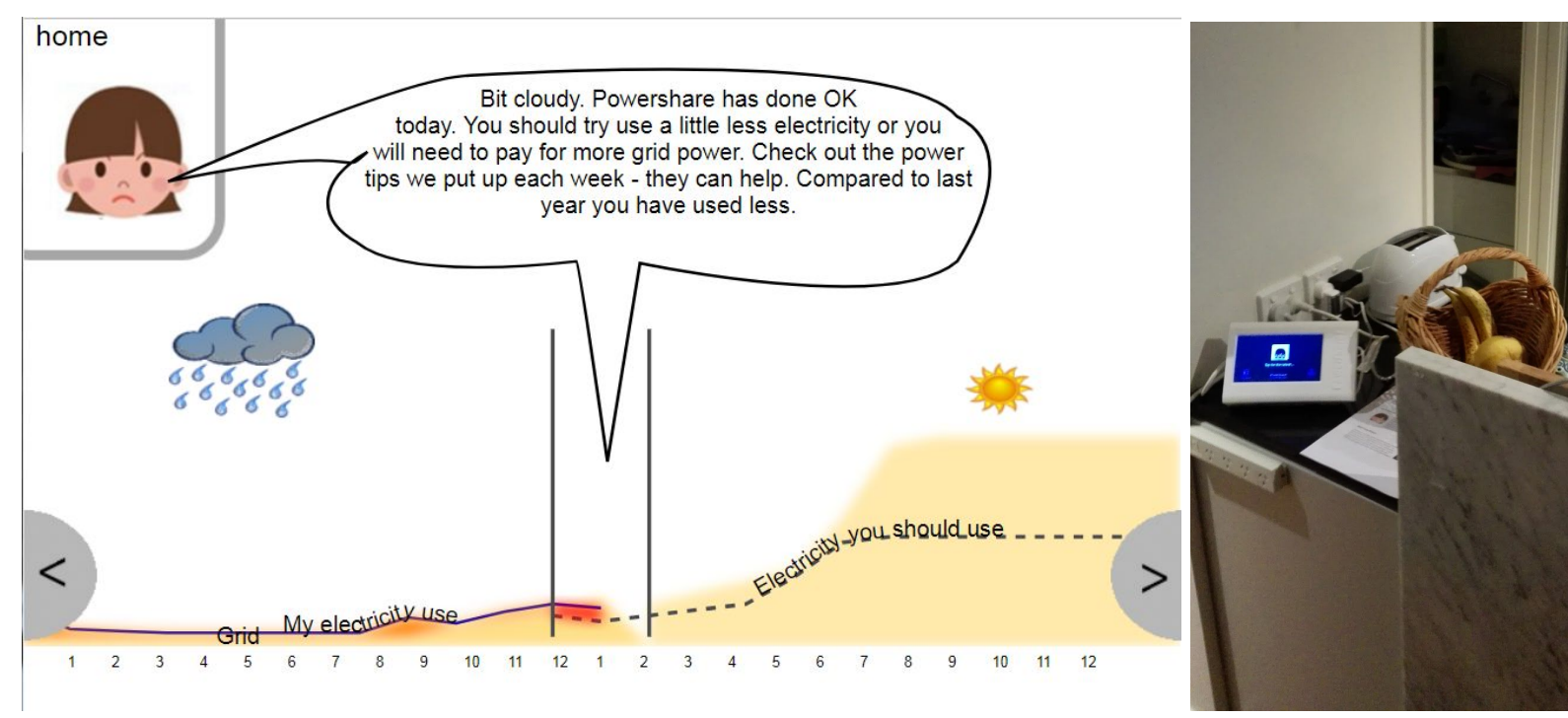

Figures 2 and 3: (left) IHD screen capture showing ten different features to reinforce conservation and shifting of demand loads toward available simulated solar and battery power. 1) A centre "goals" area of the graph shows immediate situation (at $1 \mathrm{pm}$ ) with 2) prediction at right (3) weather, 4) demand and battery/solar) and 5) performance today at left with 6) actual solar and 7) recent demand. Grid draw 8) is shown in red. Rachel an avatar, 9) emotes and gives 10) plain language versions of statistics The tabs with $<$ and $>$ are for navigating. Image of an IHD (right) in the kitchen of a participant home.

Fifteen homes took part in the study, recruited via "champions" who live among them and were reached via personal and professional networks. Five homes at one site were in a CBD apartment building. Two other sites were five homes each, freestanding 1920-30's era renovated wooden dwellings. About half the free standing homes had solar panels but the study disregarded these "real" systems and simulated a larger, shared system with battery modelled for each group. The modelling was performed with a numeric solver accepting the half-hourly aggregate demand of all participants in the group from 2017 along with previous solar records, energy costs and equipment CAPEX costs. The model produced solar and battery sizing and modelled performance for each group. This was used to configure each IHD. The size of the modelled system was broken down into unit holdings proportionate to the household demand size of 2017 so that large energy consuming households would not be unduly penalised (and small consumers would not be unduly rewarded).

Software was written for the IHD and a central server. Each IHD used its $3 G$ modem to reach the central server and report hourly on interactions the IHD experienced with the occupants. Each IHD had a reinforcement 
schedule programmed to deliver signals and interactive prompts. These are given in Table 1 below. To norm the system, government- provided energy tips selected from (Sustainability Victoria, 2014) were programmed to be delivered over 20 days along with energy use information to make sure the IHD had the impact observed of other IHDs elsewhere. Signals about the presence of the group and the limited availability of the system generation began after 20 days and from 40 days, the system detected exceptional energy demand events and solicited the group to give positive or negative feedback to a deviant home.

Table 1: Signals, schedule and function

\begin{tabular}{|l|l|}
\hline Signal and schedule & Form and purpose \\
\hline Tips 1 to 10, each 2 days & Energy saving information \\
\hline Sanctions 1 to 3, triggered during $20-40$ days & Solicit for fines for an over-using household then report the fine \\
\hline $\begin{array}{l}\text { Rewards } 1 \text { to } 3, \text { triggered triggered during } \\
20-40 \text { days }\end{array}$ & Solicit for rewards for an under-using household then report the award \\
\hline Satisfaction question each 5 days & Prompt for satisfaction with the service to detect problems \\
\hline
\end{tabular}

In addition to the timed prompts, pages of the system offered either statistics or commentary by a cartoon avatar, Rachel (Figure 1). Together with graphs these systems offered essentially the same information in three different modes. Figure 1 shows the pop up prompts that were served on top of the graphs shown in Figure 2.

A page of the system intended to reinforce a group goal, called the Paydown page, was removed close to deployment because the short run of the study meant that only three months of performance could not be effectively graphed against a payment duration of perhaps eight years. Still, commentary about paying down the system and certain statistics about this were retained.

\section{Results}

About a 100,000 event records were collected for the three groups along with a selection of 6 other homes used as controls in the period 1 Jan 2018 to 14 August 2018. The IHD signals ran for 100 days to 14 August. There were 617 interactions with the IHD collected and counted. A 4th order polynomial regression was fitted to the control group energy data series and then this spline was subtracted from the study data series to adjust for seasonal, price and other externalities. The period after 1 Jan 2018 but before May 2018 was observed for study effects which may have contributed a Hawthorne effect to the outcome. None was observed. That is, the effect of recruitment, collateral and a smart meter reader before the IHD deployment did not have an observable effect on demand and all observed effects were more likely due to the IHD and its signals.

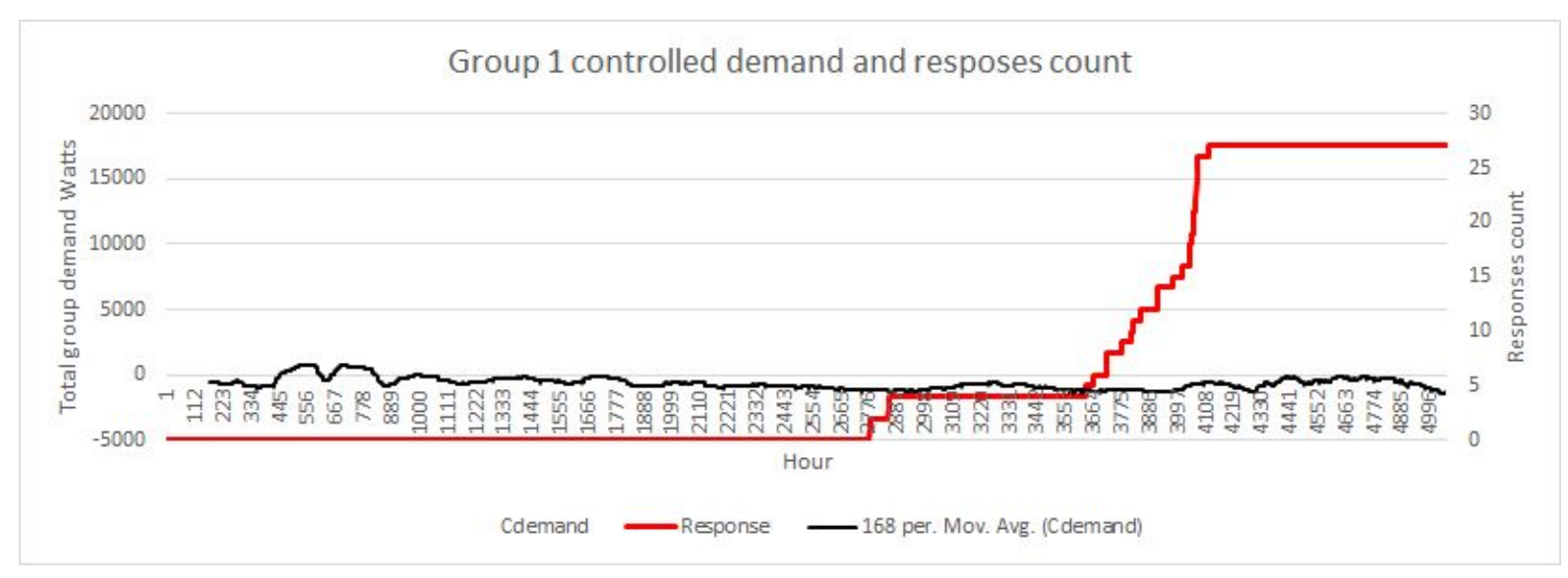


Figure 4: Group 1 responses to stimuli presented on the IHD are accumulated in red. This is plotted against moving average of a week of demand data (which have had control group effects subtracted) in black. Correlation between demand and responses in the IHD period is $r=-0.156(P=0.000)$.

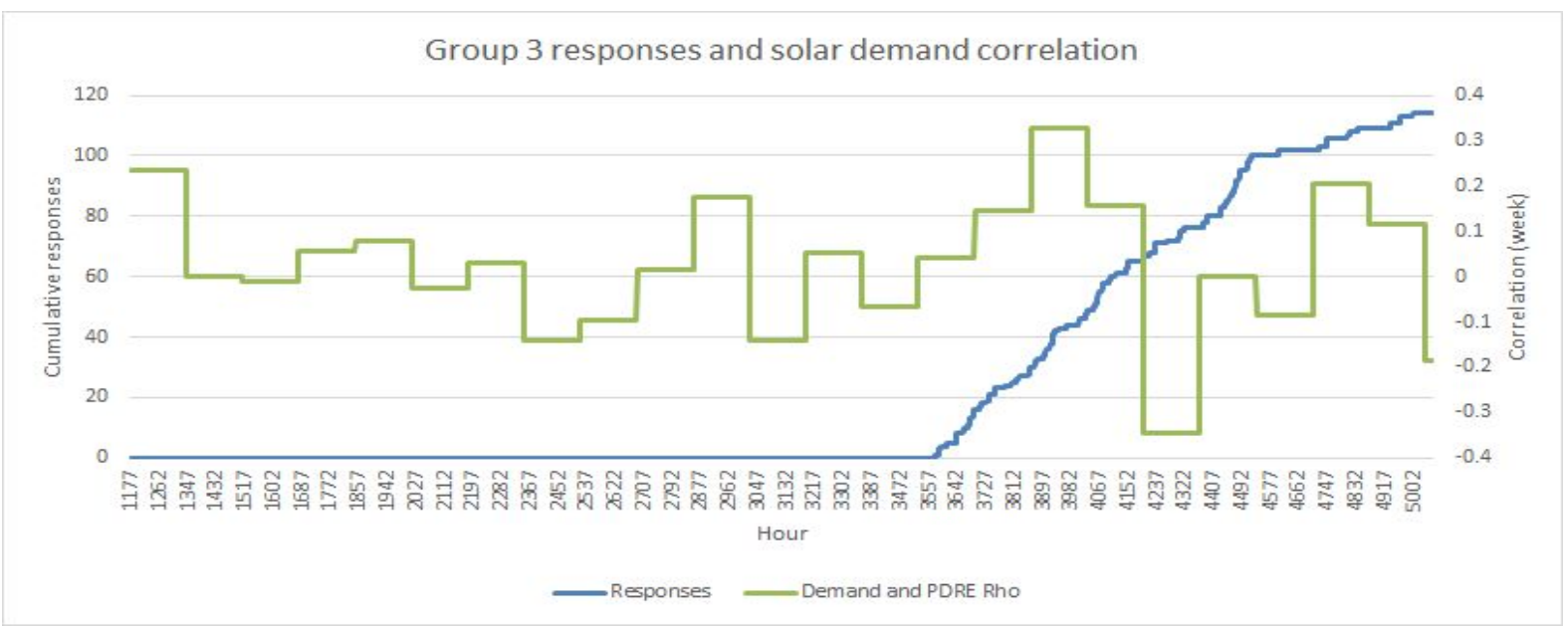

Figure 5: Group 3 Weekly Spearman's Rho correlation between PDRE and total group demand (green). Responses from the group are shown cumulatively (blue). The graph starts at hour 1177 which is when solar accounting began. From hour 2420 to the end, $r=0.12(P=0.0001)$.

Analysis of these results sought to find a negative correlation between demand and the cumulative signals with a increasing negative trend toward the end of the run to reflect increasing effects of more group- and sociallyoriented signals on consumption of electricity. As an example, Figure 4 shows group 1 cumulative responses and electricity demand. This weak but statistically significant negative correlation is present for all three groups.

Analysis determined the correlation between demand and the hourly availability of simulated solar and battery (called Past Distributed Renewable Energy - PDRE). This was determined as an indicator of load-shifting behaviour change. Figure 5 above shows group 3 weekly correlation between demand and available simulated solar and battery. The overall Spearman Rho correlation for energy demand and solar availability within the intervention period for this group was $r=0.12(P=0.0001)$. For groups 1 and 2 there was no significant correlation for time of day demand and solar-availability in the IHD period.

In the 100 days of the intervention in fact no sanctions messages were executed since no sanction events were triggered. Group messages were present from 20 days on per the schedule and are attributed to the increasing trends in declining energy use and demand-solar correlation.

\section{Discussion and Conclusions}

This study deployed a specially designed in-home display (IHD) that simulated a large, shared solar and battery systems among 3 groups of 5 adjacent homes. The signals delivered by the study in-home display simulated a commons arrangement by purporting that the shared system provided limited, rivalrous, unreliable electricity. This, together with prompts to positively or negatively message group members who under- or over- used electricity (respectively) attempted to reproduce Ostrom's (1992) forth and fifth commons principles: monitors and graduated sanctions (respectively) identified as critical to actual demand moderation.

This approach adds to the field by testing a more black-box approach to home energy use, in contrast with Bandura's Theory of Planned Behaviour (Bandura et al., 1977) which sought to modify rational behaviour in energy consumption of individual occupants. This study exploited the more modern community-as-consumer (Mackenzie-Mohr \& Smith, 1999) and simulated a large shared solar and battery system. 
The study found statistically significant support for behaviour change due to the IHD and signals. Due to the scale and short time frames of the study, outcomes for this cohort are perhaps limited in their applicability but they do indicate a promising methodology for directly testing the potential of an energy commons without the need for infrastructure or utility cooperation. In future it may also be possible to force the sanctions events since none were triggered by consumption extremes.

IHDs are a promising way to provide signals - a large Northern Ireland study found $20 \%$ demand reduction (Gans et al., 2013) but these results were not as strong in Australia before the Victorian smart meter rollout (McKerracher \& Torriti, 2013). There may be a new opportunity to pair IHDs with Victorian smart meters but also to go further a use the IHD, effectively a new messaging device, as a way to coordinate groups of homes as this study has demonstrated. The value of commons theory in this approach is promising because previous demand management studies did not reframe electricity as different from high available, unlimited and highly reliable. Renewable supply will not match these qualities and instead requires a kind of compromise between demand behaviour, available power and conservation. The greater agency of people in groups is already important for environmental conservation more broadly (Bandura, 2000) and the very difficult challenge of changing social practices around energy should also be a social effort. Shared energy can exploit these opportunities and commons theory provides a very rich history of stable, non-market, self-governing social efforts around critical limited resources.

This study does not propose urban off-grid communities but it may be possible for a private microgrid to be legally off grid (islanded) for electricity exchanges. The grid utility provides considerable value but it does not provide effective signals to moderate demand and the GHG emissions from electricity are very great. Instead, the modelling in this study showed a majority of electricity needed by a group of homes can be obtained efficiently (both in terms of energy and cost) from a shared solar system but also in concert with a demand management programme. This approach should be explored further for its potential to bring about substantial shifting- and reduction- of energy demand if renewable generation is to plausibly meet our future demand.

\section{Acknowledgement}

This research was funded along with scholarship RP5005 supported by the Low Carbon Living CRC.

\section{References}

Abbott, M. (2001). Is the Security of Electricity Supply a Public Good? Electricity Journal, 14(7), 31-33.

Abrahamse, W., Steg, L., Vlek, C., \& Rothengatter, T. (2005). A review of intervention studies aimed at household energy conservation. Journal of Environmental Psychology, 25(3), 273-291.

AEMO. (2013). 100 PER CENT RENEWABLES STUDY - MODELLING OUTCOMES. Australian Energy Market Operator. Retrieved from

https://www.environment.gov.au/system/files/resources/d67797b7-d563-427f-84eb-c3bb69e34073/fil es/100-percent-renewables-study-modelling-outcomes-report.pdf

Allon, F., \& Sofoulis, Z. (2006). Everyday Water: cultures in transition. The Australian Geographer, 37(1), 45-55.

Australian Bureau of Meteorology. (2014, June). What is El Niño and what might it mean for Australia? Retrieved June 2, 2018, from http://www.bom.gov.au/climate/updates/articles/a008-el-nino-and-australia.shtml

Bandura, A. (2000). Exercise of Human Agency Through Collective Efficacy. Current Directions in Psychological Science, 9(3), 75-78.

Bandura, A., Boone, T., Reilly, A., \& Sashkin, M. (1977). SOCIAL LEARNING THEORY (Vol. 2). Prentice-Hall, SAGE Publications, Englewood Cliffs, N.J.

Bauwens, T., \& Eyre, N. (2017). Exploring the links between community-based governance and sustainable energy use: Quantitative evidence from Flanders. Ecological Economics: The Journal of the International Society for Ecological Economics, 137, 163-172.

Bollier, D. (2014). Think Like a Commoner: A Short Introduction to the Life of the Commons. New Society Publishers. 
Cox, M., Arnold, G., \& Villamayor Tomás, S. (2010). A review of design principles for community-based natural resource management. Ecology and Society, 15(4), 38.

CSIRO and ENA. (2015). Electricity Network Transformation Roadmap - Interim Program Report. Energy Networks Association. Retrieved from http://www.energynetworks.com.au/sites/default/files/roadmap_interim_report_final.pdf

DEE. (2018). Independent Review of the Greenhouse and Energy Minimum Standards (GEMS) Act 2012. Department of the Environment and Energy. Retrieved from http://www.energyrating.gov.au/sites/new.energyrating/files/documents/GEMS\%20Review\%20-\%20F INAL\%20Discussion\%20Paper_20180228\%2B\%2B.pdf

Delmas, M. A., Fischlein, M., \& Asensio, O. I. (2013). Information strategies and energy conservation behavior: A meta-analysis of experimental studies from 1975 to 2012. Energy Policy, 61, 729-739.

DELWP. (2014, August 13). Top 10 ways to save energy. Retrieved July 19, 2017, from https://www.victorianenergysaver.vic.gov.au/more-ways-to-save/top-10-ways-to-save-energy

DELWP. (2016). Standard Feed-in Tariff and Transitional Feed-in Tariff - DELWP. Retrieved March 31, 2017, from

http://delwp.vic.gov.au/energy/electricity/victorian-feed-in-tariff/closed-feed-in-tariff-schemes/standard -feed-in-tariff-and-transitional-feed-in-tariff

Gans, W., Alberini, A., \& Longo, A. (2013). Smart meter devices and the effect of feedback on residential electricity consumption: Evidence from a natural experiment in Northern Ireland. Energy Economics, 36, 729-743.

Gardiner, K. (2017, March 30). The small Scottish isle leading the world in electricity. Retrieved September 29, 2017, from http://www.bbc.com/future/story/20170329-the-extraordinary-electricity-of-the-scottish-island-of-eigg

Hargreaves, T., Nye, M., \& Burgess, J. (2008). Social experiments in sustainable consumption: an evidence-based approach with potential for engaging low-income communities. Local Environment, 13(8), 743-758.

Hill, J. (2014, July 1). Power corrupts. Retrieved August 30, 2018, from https://www.themonthly.com.au/issue/2014/july/1404136800/jess-hill/power-corrupts

Ison, N., \& Lyons, M. (2013). Homegrown Power Plan Summary. GetUp and SolarCitizens.

Kelly, M. J. (2010). Future Energy Needs and Engineering Reality. Retrieved from http://www.nscj.co.uk/JECM/issues/JECM-1-3.pdf

Liubinas, A., \& Harrison, P. (2012). Saving a Scarce Resource: A Case Study of Behavioural Change. In Academy of Marketing Conference.

Lowe, B., Lynch, D., \& Lowe, J. (2015). Reducing household water consumption: a social marketing approach. Journal of Marketing Management, 31(3-4), 378-408.

Mackenzie-Mohr, D., \& Smith, W. F. S. B.-A. (1999). Introduction to Community-Based Social Marekting. Gabriola Island New Society Publishers.

McKerracher, C., \& Torriti, J. (2013). Energy consumption feedback in perspective: integrating Australian data to meta-analyses on in-home displays. Energy Efficiency, 6(2), 387-405.

Ostrom, E., Gardner, R., Walker, J., \& Walker, J. (1994). Rules, Games, and Common-pool Resources. University of Michigan Press.

Russell-Bennett, R., Bedggood, R., Glavas, C., Swinton, T., McAndrew, R., O'Mahony, C., ... Willand, N. (2017). Power Shift Project One: Driving Change - Identifying what Caused Low-Income Consumers to Change Behaviour, Final Report. Queensland University of Technology and Swinburne University of Technology.

Shove, E., \& Walker, G. (2014). What Is Energy For? Social Practice and Energy Demand. Theory, Culture \& Society, 31(5), 41-58.

SmartUser. (2018). Watts Clever Energy Monitor - EW4500 - smartuser. Retrieved July 23, 2018, from http://www.smartuser.com.au/product/watts-clever-energy-monitor-ew4500/

Sustainability Victoria. (2014). Household Energy Action Guide. Victorian State Government. Retrieved from http://www.sustainability.vic.gov.au/-/media/SV/Publications/You-and-your-home/Save-energy/House holds-Energy-Action-Guide.pdf 
Wood, T., Carter, L., \& Harrison, C. (2014). Fair pricing for power. Grattan Institute Melbourne, Australia. 